University of Nebraska - Lincoln

DigitalCommons@University of Nebraska - Lincoln

Management Department Faculty Publications

Management Department

2007

\title{
Development of a global measure of job embeddedness and integration into a traditional model of voluntary turnover
}

\author{
Craig Crossley \\ University of Nebraska, Lincoln, ccrossley2@unl.edu \\ Rebecca J. Bennett \\ Louisiana Tech University, rbennett@latech.edu \\ Steve M. Jex \\ Bowling Green State University, sjex@bgnet.bgsu.edu \\ Jennifer L. Burnfield \\ Human Resources Research Organization, Alexandria, Virginia
}

Follow this and additional works at: https://digitalcommons.unl.edu/managementfacpub

Part of the Management Sciences and Quantitative Methods Commons

Crossley, Craig; Bennett, Rebecca J.; Jex, Steve M.; and Burnfield, Jennifer L., "Development of a global measure of job embeddedness and integration into a traditional model of voluntary turnover" (2007). Management Department Faculty Publications. 34.

https://digitalcommons.unl.edu/managementfacpub/34

This Article is brought to you for free and open access by the Management Department at DigitalCommons@University of Nebraska - Lincoln. It has been accepted for inclusion in Management Department Faculty Publications by an authorized administrator of DigitalCommons@University of Nebraska - Lincoln. 
Published in Journal of Applied Psychology 92:4 (2007), pp. 1031-1042; doi 10.1037/0021-9010.92.4.1031

Copyright (c) 2007 American Psychological Association. Used by permission. "This article may not exactly replicate the final version published in the APA journal. It is not the copy of record."

The authors thank Bruce Avolio, Robert Gibby, Brooks Holtom, Tom Lee, Marie Mitchell, Mary Uhl-Bien, and Brad West for their helpful comments and suggestions.

Submitted March 25, 2006; revised September 18, 2006; accepted October 23, 2006.

\title{
Development of a global measure of job embeddedness and integration into a traditional model of voluntary turnover
}

\author{
Craig D. Crossley, Gallup Leadership Institute, College of Business Administration, University of Nebraska-Lincoln \\ Rebecca J. Bennett, Department of Management, Louisiana Tech University \\ Steve M. Jex, Department of Psychology, Bowling Green State University \\ Jennifer L. Burnfield, Human Resources Research Organization, Alexandria, Virginia \\ Corresponding author - Craig D. Crossley, Gallup Leadership Institute, College of Business Administration, \\ University of Nebraska-Lincoln, Lincoln, NE 68588; email ccrossley2@unl.edu
}

\begin{abstract}
Recent research on job embeddedness has found that both on- and off-the-job forces can act to bind people to their jobs. The present study extended this line of research by examining how job embeddedness may be integrated into a traditional model of voluntary turnover. This study also developed and tested a global, reflective measure of job embeddedness that overcomes important limitations and serves as a companion to the original composite measure. Results of this longitudinal study found that job embeddedness predicted voluntary turnover beyond job attitudes and core variables from traditional models of turnover. Results also found that job embeddedness interacted with job satisfaction to predict voluntary turnover, suggesting that the job embeddedness construct extends beyond the unfolding model of turnover (T. R. Mitchell \& T. W. Lee, 2001) it originated from.
\end{abstract}

For decades, research on employee turnover has focused on job dissatisfaction and perceived alternatives as catalysts for quitting one's job. Indeed, March and Simon's (1958) seminal work suggested that turnover is a function of the perceived ease of movement and the desirability of leaving one's job. In the wake of this research, much of the theoretical landscape of voluntary turnover to date has been shaped by conceptual models posited in the 1970s and early 1980s by scholars such as Mobley (1977; Mobley, Horner, \& Hollingsworth, 1978); Katzell, Korman, and Levine (1971); Muchinsky and Morrow (1980); Price (1977); and Steers and Mowday (1981).

One notable exception to this traditional paradigm is Lee and Mitchell's (1994) unfolding model of voluntary turnover. This unique perspective on turnover posits alternative pathways to voluntary turnover that are not induced by job dissatisfaction. One important implication emerging from this research is that whereas quitting a job is often preceded by some degree of mental consideration (e.g., comparison with alternative jobs), remaining with an organization may simply be the result of maintaining the status quo. On the basis of this notion, Lee, Mitchell, Sablynski, Burton, and Holtom (2004; Mitchell, Holtom, Lee, Sablynski, \& Erez, 2001; Mitchell \& Lee, 2001) argued that people can become stuck or "embedded" in their job as a result of various organizational and community-related forces. Job embeddedness has been defined as "the combined forces that keep a person from leaving his or her job" (Yao, Lee, Mitchell, Burton, \& Sablynski, 2004, p. 159) and includes factors such as marital status, community involvement, and job tenure.
Notwithstanding the important theoretical advances of job embeddedness, there exist several limitations of the original measure. Recognizing these concerns, Mitchell et al. (2001) encouraged future research improving the measurement of embeddedness. Thus, the first aim of this study is to answer this call for research and offer a global measure of job embeddedness that addresses some of the shortcomings of the original composite measure. The second aim of this study is to integrate the recently developed job embeddedness construct with a traditional model of voluntary turnover and decades of prior research. Whereas recent research on job embeddedness has supported direct relations with turnover (Mitchell et al., 2001), the present study examines the interactive relationship between job embeddedness and dissatisfaction.

\section{Toward a Global Measure of Job Embeddedness}

Job embeddedness was posited as a construct composed of contextual and perceptual forces that bind people to the location, people, and issues at work (Yao et al., 2004). To date, this construct has been operationalized as a composite of two mid-level subfactors: on-the-job embeddedness and off-the-job embeddedness (Mitchell et al., 2001). Whereas on-the-job embeddedness refers to how enmeshed a person is in the organization where he or she works, off-the-job embeddedness relates to how entrenched a person is in his or her community. Each of these forms of embeddedness is represented by three underlying facets: links (formal or informal connections between a per- 
son and institutions, locations, or other people), fit (employees' compatibility or comfort with work and nonwork environments), and sacrifice (cost of material or psychological benefits that one may forfeit by leaving one's job or community).

The composite measure of job embeddedness (Mitchell et al., 2001) is formed when one adds together equally weighted facets, assuming that the whole is equal to the sum of its parts. In contrast, a global measure of embeddedness would assume that the whole is greater than the sum of its parts and assess overall impressions of attachment by asking general questions. This approach suggests that some sort of mental processing occurs and simply asks for the end product. During this process, respondents subjectively weigh various facets and may even incorporate additional relevant information that might have been omitted from facet-level scales.

Composite measures do not necessarily lead to the same results as global scales and may be inadequate for estimating summary evaluations, theoretically limiting such constructs in several ways (Ironson, Smith, Brannick, Gibson, \& Paul, 1989). For instance, composites may omit some areas that may be important to the individual or include some areas that may be irrelevant, leading to construct deficiency or contamination, respectively. Furthermore, combining scales in an additive fashion may ignore the unique importance that individuals place on different facets when forming a summary perception (Rice, Gentile, \& McFarlin, 1991). Thus, a global measure of job embeddedness allows those employees whose job change does not require a move to place less weight on communityrelated aspects while allowing those who would have to leave the community to place a greater weight on these facets.

Aside from the theoretical limitations of the composite measure of job embeddedness, there are important practical and statistical considerations that warrant further attention. In terms of practical limitations, the personal nature of some items (e.g., marital status, home ownership) may be viewed as an invasion of privacy, provoking socially desirable responding or the intentional skipping of questions. Furthermore, the length of the measure (i.e., 40 items) may limit its use in organizational surveys and may further lead to fatigue and acquiescent responding (Breaugh \& Colihan, 1994). Because composite measures assume complete coverage of a construct domain, simply reducing scale length may jeopardize content validity (MacKenzie, Podsakoff, \& Jarvis, 2005). A global measure of embeddedness overcomes these limitations by asking general, noninvasive questions regarding how enmeshed people are in their job, regardless of personal reasons. Staying at a general level also allows the entire construct to be assessed with relatively few questions.

In terms of statistical limitations, the composite job embeddedness scale constitutes a mixed measure of reflective and formative items. A reflective scale is composed of parallel items to which responses are "caused" by the same underlying latent construct. Conversely, a formative scale is composed of items that, when combined, constitute or cause the construct. For instance, being married or owning their home may cause people to be embedded in their job, whereas being embedded in their job does not cause people to get married or own a home. Additionally, owning a home and being married are not conceptually parallel or equivalent. Thus, use of causal indicators to create a formative measure of job embeddedness renders questionable the appropriateness of common methods for evaluating scale properties, such as coefficient alpha and factor analysis, as well as latent variable analyses, such as structural equation modeling (MacKenzie et al., 2005). A second statistical limitation of the composite embeddedness measure is the use of varying response formats, which can create statistical artifacts (Harvey, Billings, \& Nilan, 1985). Finally, including both facets and their summative composite in the same model can lead to problems of singularity, an extreme case of multicollinearity, as higher level variables are redundant with lower level facets. A global assessment of job embeddedness constitutes a reflective construct that can be assessed with items that use the same response format, enabling it to overcome these statistical limitations.

\section{Construct Comparisons}

Job embeddedness is distinct from similar constructs, such as job satisfaction and organizational commitment, in several important ways. More specific distinctions are provided in Table 1 , but there are two essential differences worth noting here. First, whereas job satisfaction and organizational commitment focus on job-related factors, job embeddedness includes community-related issues in addition to job-related issues. Thus, as much as half of the job embeddedness construct is not covered by organization-focused constructs (Mitchell et al., 2001). A second critical distinction is based on Maertz and Campion's (2004) content model of turnover, which suggests that people have different motives for staying or leaving. These motives include affective reasons (membership provides positive emotions), calculative reasons (expectancy of future value attainment), alternatives (whether one is capable of obtaining an alternative job), and normative reasons (desire to meet expectations of family or friends), among others. According to this model, job satisfaction and the various forms of commitment represent specific reasons for being attached. In contrast, job embeddedness represents a general attachment construct that assesses the extent to which people feel attached, regardless of why they feel that way, how much they like it, or whether they chose to be so attached. The distinction between job embeddedness and related constructs is of particular importance when one considers broad theories of job mobility, in which the reasons why people are attached are of less importance than the extent to which they are attached.

\section{Traditional Models of Turnover}

Mobley (1977) proposed a multistage model of processes and intermediate linkages whereby dissatisfaction relates to voluntary turnover. The majority of research examining the voluntary turnover process has tested this model or a modified version of it (see Bannister \& Griffeth, 1986). Although models and measures have varied, results have tended to converge around the importance of dissatisfaction, perceived alternatives, intentions to search, and quit intentions as four core antecedents of voluntary turnover (Steel, 2002).

Lee and Mitchell (1994) posited that employees may not follow the rational decision path purported by Mobley and others (see Bannister \& Griffeth, 1986; Mobley, 1977, Mobley et al., 1978), instead conserving mental resources by automatically screening alternatives, acting on prescripted behavior (e.g., "If that person ever becomes my boss, I will quit"), and 
Table 1. Distinctions Between Job Embeddedness and Related Constructs

\begin{tabular}{|c|c|c|}
\hline Construct & Definition & Distinction from job embeddedness \\
\hline Job satisfaction & $\begin{array}{l}\text { The extent to which people like (satisfaction) or } \\
\text { dislike (dissatisfaction) their jobs (Spector, 1997). }\end{array}$ & $\begin{array}{l}\text { Job embeddedness (a) represents factors outside of the workplace and } \\
\text { (b) is not always affective in nature. }\end{array}$ \\
\hline $\begin{array}{l}\text { Continuance } \\
\text { commitment }\end{array}$ & $\begin{array}{l}\text { Commitment based on the employee's } \\
\text { recognition of the costs associated with } \\
\text { leaving the organization (Allen \& Meyer, } \\
\text { 1996). Includes side bets and perceived } \\
\text { alternatives. }\end{array}$ & $\begin{array}{l}\text { Job embeddedness (a) includes community-related factors not typically } \\
\text { included in continuance commitment (e.g., a safe community, } \\
\text { spouse's employment, leisure activities, weather and climate), } \\
\text { (b) includes both affective- and cognitive-based evaluations, (c) is } \\
\text { focused on the past (status quo) as well as the future, and (d) is not } \\
\text { limited to attachment based specifically on lack of options or forfeited } \\
\text { investments in the organization. }\end{array}$ \\
\hline $\begin{array}{l}\text { Normative } \\
\text { commitment }\end{array}$ & $\begin{array}{l}\text { Commitment based on a sense of obligation or } \\
\text { that staying is the right and moral thing to } \\
\text { do. Posited to develop on the basis of } \\
\text { socialization experiences in one's early life, } \\
\text { including family-based and culturally based } \\
\text { experiences (Allen \& Meyer, 1996). }\end{array}$ & $\begin{array}{l}\text { Job embeddedness (a) represents factors outside of the workplace } \\
\text { and (b) is descriptive in nature and does not necessarily relate to } \\
\text { how right or wrong it is to be so attached. }\end{array}$ \\
\hline $\begin{array}{l}\text { Intentions to } \\
\text { quit }\end{array}$ & $\begin{array}{l}\text { Individuals' own estimated probability } \\
\text { (subjective) that they are permanently leaving } \\
\text { the organization at some point in the near } \\
\text { future (Vandenberg \& Nelson, 1999). Based } \\
\text { on mental consideration of (a) the behavior, } \\
\text { (b) the target object toward which the } \\
\text { behavior is directed, (c) the situational } \\
\text { context in which the behavior will be } \\
\text { performed, and (d) the time at which the } \\
\text { behavior is to occur (Fishbein \& Ajzen, 1975). }\end{array}$ & $\begin{array}{l}\text { Job embeddedness represents a present status quo based on inertia-like } \\
\text { forces shaped from the past, whereas intentions to quit represent } \\
\text { anticipated future behaviors. Intentions to quit are regarded as the } \\
\text { culmination of the decision process regarding turnover and represent } \\
\text { a transitional link between thought processes and behavioral action } \\
\text { (Mobley, 1977). }\end{array}$ \\
\hline
\end{tabular}

so on. These authors also introduced the notion of a shock or jarring event, such as receiving an unanticipated job offer, being overlooked for a promotion, or experiencing a family issue such as a birth or death (Holtom, Mitchell, Lee, \& Interrieden, 2005). Shocks represent distinctly different concepts than dissatisfaction and are used to distinguish Lee and Mitchell's model from traditional models of turnover.

Mitchell and Lee (2001) posited that job embeddedness prohibits turnover by absorbing shocks. Nevertheless, the limited research linking embeddedness to turnover has examined only main effects (Mitchell et al., 2001) and has not directly tested this buffering hypothesis. Furthermore, the persistence of dissatisfaction in explaining voluntary turnover (e.g., $42 \%$; Holtom et al., 2005) underscores the need for examining how job embeddedness can be integrated into traditional models. Job embeddedness may be viewed as a unique contextual factor that independently relates to turnover, beyond other core aspects of traditional models. This notion has received some empirical support (Mitchell et al., 2001) and is similar to Mossholder, Settoon, and Henagan's (2005) proposition that the absence of social attachments may create a contextual force or tension that pushes employees from the organization. In an effort to replicate previous research and to further extend the scope of outcomes to the constellation of core turnover variables specified in traditional models, we propose the following hypotheses:
Hypothesis 1A: Job embeddedness will predict intention to search and intention to quit, beyond job satisfaction and perceived alternatives.

Hypothesis 1B: Job embeddedness will predict voluntary turnover, beyond job satisfaction, perceived alternatives, intention to search, and intention to quit.

The composite measure of job embeddedness contains both contextual (e.g., home ownership) and perceptual (e.g., felt similarity to coworkers) items and relates to what Lewin (1951) termed the psychological field, which includes both recognized and unrecognized forces that influence behavior. Conversely, a global measure of embeddedness integrates only those recognized factors that are important to forming an overall impression of how embedded a person feels. Accordingly, a global measure of job embeddedness represents one's phenomenal field, reflecting the sum of all recognized forces binding one to one's job.

Whereas traditional models of turnover are based on a series of cognitive deliberations and discretionary behaviors, the formation of intentions may be influenced to a greater extent by perceived variables that may enter into rational thought than by more contextual forces that might influence behavior but not through rational thought. Also, because perceptions are influenced by more than just objective conditions, they of- 
ten account for incremental variance beyond more objective measures. For example, laboratory studies have found that the perception of control was a more powerful predictor of performance and coping than was objective control (Endler, Macrodimitris, \& Kocovski, 2000). In a similar vein, perceived job fit has been found to predict unique variance over objective job fit (see Kristof, 1996).

On the basis of a growing body of research suggesting that perceptions exert a greater influence on discretionary behaviors than do their more objective counterparts and also on the basis of the notion that global measures include synergies between facets captured by subjective weightings to create a whole that is greater than the sum of the parts, global perceptions of job embeddedness are expected to predict unique variance in intention to search, intention to quit, and turnover beyond composite job embeddedness.

Hypothesis 2: The global measure of job embeddedness will predict intention to search, intention to quit, and voluntary turnover over the composite measure.

Although the notion of job embeddedness stemmed from implications surrounding shocks and jarring events that lead some people to leave while others stay, embeddedness may extend beyond the specific paths in the unfolding model (Lee \& Mitchell, 1994) that are provoked by shock-related events or information. Whereas festering job dissatisfaction is qualitatively different than an abrupt shock, Mitchell and Lee (2001) used shocks versus dissatisfaction as a key factor in distinguishing turnover paths. However, the buffering effect of embeddedness need not be limited to shocks. Rather, job embeddedness may also dissipate dissatisfaction in much the same way as it is posited to absorb shocks. Indeed, embeddedness may defer the gradual buildup of dissatisfaction, deflecting energy away from search-related efforts and intentions. However, because of the highly cognitive and logical links that underlie the relation between dissatisfaction and intentions to search, this moderating effect is expected to occur at the perceptual level, among global impressions of embeddedness and feelings of dissatisfaction. That is, how satisfied one feels and how embedded one thinks oneself to be are posited to jointly affect the formation of job search intentions.

Hypothesis 3: Global job embeddedness will moderate the relation between job satisfaction and intentions to search, such that the negative relationship between job satisfaction and intention to search will be stronger under conditions of low embeddedness.

\section{Method}

\section{Participants}

Participants represented a cross-section of employees from a mid-sized organization in the midwestern United States that provides assisted living for older adults and disabled youths. We administered and collected three separate surveys during regularly scheduled meetings at two points in time, approximately 1 month apart. On the basis of the conceptual closeness of turnover-related attitudes and intentions (Tett \& Meyer, 1993) and prior research detecting significant relations between attitudes and active job search behaviors over relatively short time spans (e.g., 6 weeks; Crossley \& Stanton, 2005), in the present study we used a 1-month span to separate attitudes and intentions. This short time span also helped reduce memory decay. In an effort to further reduce perceptpercept inflation (see Podsakoff, MacKenzie, Lee, \& Podsakoff, 2003), we temporally separated the two surveys collected at the first meeting (Time 1A and $1 \mathrm{~B}$ ) by a 15-min break to create a cognitive interruption. Of the 616 employees of the organization, 318 completed all parts of the survey and provided necessary information to link responses. Because this study focuses on voluntary turnover, those individuals $(n=12)$ who left the organization because of other reasons (e.g., retirement, poor performance) were not included in analyses. From the remaining sample of 306, 80\% were female; ages ranged from 18 to 73 years $(M=42.2, S D=13.78)$. Eighty-three percent of the participants identified themselves as White or Caucasian, 13\% identified as Black, 2\% identified as Latino, and 2\% identified as other ethnicities. Tenure with the organization ranged from 1 month to 36 years $(M=5.6$ years, $S D=6.77)$; $76 \%$ of participants held line positions, $19 \%$ held managerial positions, and $5 \%$ held executive positions.

\section{Measures}

Composite job embeddedness (Time 1B). Composite job embeddedness was measured with the 40-item measure developed by Mitchell et al. (2001). All facets except community and organizational links used a 5 -point response scale $(5=$ strongly agree). The Organization Fit subscale comprised 9 items, such as "My coworkers are similar to me" $(\alpha=.87)$. Organizational Links included 7 items, such as "How many coworkers are highly dependent on you?" ( $\alpha=.68)$. Organization Sacrifice was composed of 10 items, such as "I would sacrifice a lot if I left this job" $(\alpha=.86)$. The 5-item Community Fit subscale included items such as "The area where I live offers the leisure activities that I like" $(\alpha=.86)$. Community links were assessed with a 6-item subscale composed of items such as "Are you currently married?" "Do you own the home you live in?" and "How many family members live nearby?" $(\alpha=.58)$. The Community Sacrifice subscale was composed of 3 items, such as "People respect me a lot in my community" $(\alpha=.70)$. Because response options differed across items, all item responses were standardized before being combined into respective scales.

Global job embeddedness (Time 1B). We followed a number of guidelines in writing items for the global job embeddedness scale. First, using Hinkin's (1995) deductive item-generation strategy, we obtained both published articles and works in progress from authors known to be studying job embeddedness and thoroughly examined them for clear examples and construct definitions from which reflective items could be developed. As a lengthy questionnaire can lead to careless responding (Breaugh \& Colihan, 1994), we gave consideration to developing a small number of items that would adequately capture the content domain. On the basis of these guidelines, we generated a list of items that we circulated among colleagues for comments and revised accordingly. This process resulted in seven original items, reported in Table 2.

To provide an initial assessment of the factor structure and reliability, we distributed these items to a unique sample of 87 nurses and drug rehab counselors who worked in different organizations than the major sample used to test hypotheses. As 
Table 2. Factor Loadings of Global Job Embeddedness Items

\begin{tabular}{lll}
\hline Item & Study 1 & $\begin{array}{c}\text { Study } 2 \\
\lambda\end{array}$ \\
\hline I feel attached to this organization. & $\lambda$ & .89 \\
It would be difficult for me to leave this organization. & .82 & .90 \\
I'm too caught up in this organization to leave. & .82 & .42 \\
I feel tied to this organization. & .58 & .68 \\
I simply could not leave the organization that I work for. & .63 & .65 \\
It would be easy for me to leave this organization. ${ }^{a}$ & .68 & .74 \\
I am tightly connected to this organization. & .83 & .84 \\
\hline
\end{tabular}

Study 1 reports factor weights from principal-axis exploratory factor analysis. Study 2 reports standardized factor weights from confirmatory factor analysis via maximum-likelihood estimation.

a Item was reverse-scored.

no a priori multidimensional structure was hypothesized and in light of the modest sample size, we subjected items to exploratory factor analysis using principal-factors extraction with oblique rotation. Results suggested a single-factor solution that accounted for $51 \%$ of the total variance. Cronbach's alpha for the scale was .88, and item-total correlations ranged from .60 to .75 . On the basis of these results, we retained all items for use in the present study.

As with the pilot study, participants from the caregiving organization were asked to indicate their level of agreement with each item on a 5 -point scale $(5=$ strongly agree). The factor structure of the global job embeddedness scale was assessed in this sample via confirmatory factor analysis with maximum likelihood estimation. This confirmatory factor analysis, $\chi^{2}(14$, $N=306)=79.95, p<.05$, achieved good fit to the data, as assessed by a comparative fit index (CFI) value of .94 , a goodness-of-fit index (GFI) value of .93, and a standardized rootmean-square residual (SRMR) value of .04. The alpha internal consistency estimate for the scale was .89. Factor loadings are reported in Table 2.

Job satisfaction (Time 1A). Job satisfaction was measured with the eight-item Abridged Job in General Scale (Russell et al., 2004). Participants were asked to indicate whether adjectives and short phrases, such as "good" and "better than most," described their job on a yes-no-? response format.

Job alternatives (Time 1A). Inasmuch as previous research has failed to converge on a single, commonly used measure of perceived job alternatives, the present study used the following three items based on Steel and Griffeth's (1989) review of the job alternatives construct: "I know of several job alternatives that I could apply for," "I have concrete alternative job offers in hand," and "It would be easy for me to find another job that pays as well as my present job" $(5=$ strongly agree $)$.

Job search intention (Time 2). Whereas previous research has typically assessed cognitive aspects of job search intentions, often at the same time as cognitive ratings of intentions to quit, the present study assessed behavioral manifestations of search intention via the six-item preparatory job search scale developed by Blau (1994). Because search intentions are theoretically posited to occur after job dissatisfaction and before cognitive intentions to quit are formed, we adopted this measure to address preparatory job search actions that temporally spanned the 4 weeks between survey administrations. This provided an important methodological advance and was intended to reduce spurious correlations that may occur when one simultaneously assesses cognitive-based intentions to search and cognitive-based intentions to quit. Participants were asked to indicate how much time they had spent on preparatory search activities, such as revising their resume, on a scale anchored at $1=$ zero times and $5=$ at least 10 times.

Intentions to quit (Time 2). Intentions to quit were assessed with a five-item scale (Crossley, Grauer, Lin, \& Stanton, 2002) that was designed to avoid content overlap with measures of job search and job attitudes (Tett \& Meyer, 1993). Participants responded on a 7-point scale ( 7 = strongly agree) to the following items: "I intend to leave this organization soon," "I plan to leave this organization in the next little while," "I will quit this organization as soon as possible," "I do not plan on leaving this organization soon" (reverse scored), and "I may leave this organization before too long."

Turnover (Time 3). Employee records provided data regarding whether participants remained with $(n=277)$ or had voluntarily quit $(n=29)$ the organization 1 year after completing the survey. To ensure that turnover was voluntary rather than the result of felt pressures to leave, we correlated turnover with a four-item measure developed for this study (Time 1B; e.g., "I feel pressured into leaving this organization," "My coworkers make me feel welcome and wanted here" [reverse scored]; $5=$ strongly agree; $\alpha=.69$ ). The nonsignificant correlation $(r=.07)$ suggested that those who left did not feel pressured to do so.

Control variables. In an effort to demonstrate discriminant validity of job embeddedness over organizational commitment, in the present study we measured (Time 1A) and statistically controlled for empirical overlap between both affective and continuance commitment and job embeddedness. We measured affective commitment using Meyer and Allen's (1997) six-item scale composed of items such as "I would be happy to spend the rest of my career with this organization." We measured continuance commitment with Meyer and Allen's six-item scale composed of items such as "One of the major reasons I continue working for this organization is that leaving would require considerable personal sacrifice-another organization might not match my overall benefits here" $(5=$ strongly agree $)$.

\section{Results}

\section{Evidence of Construct Validity}

Table 3 displays descriptive statistics and intercorrelations between the study variables. Given that employees' global per- 


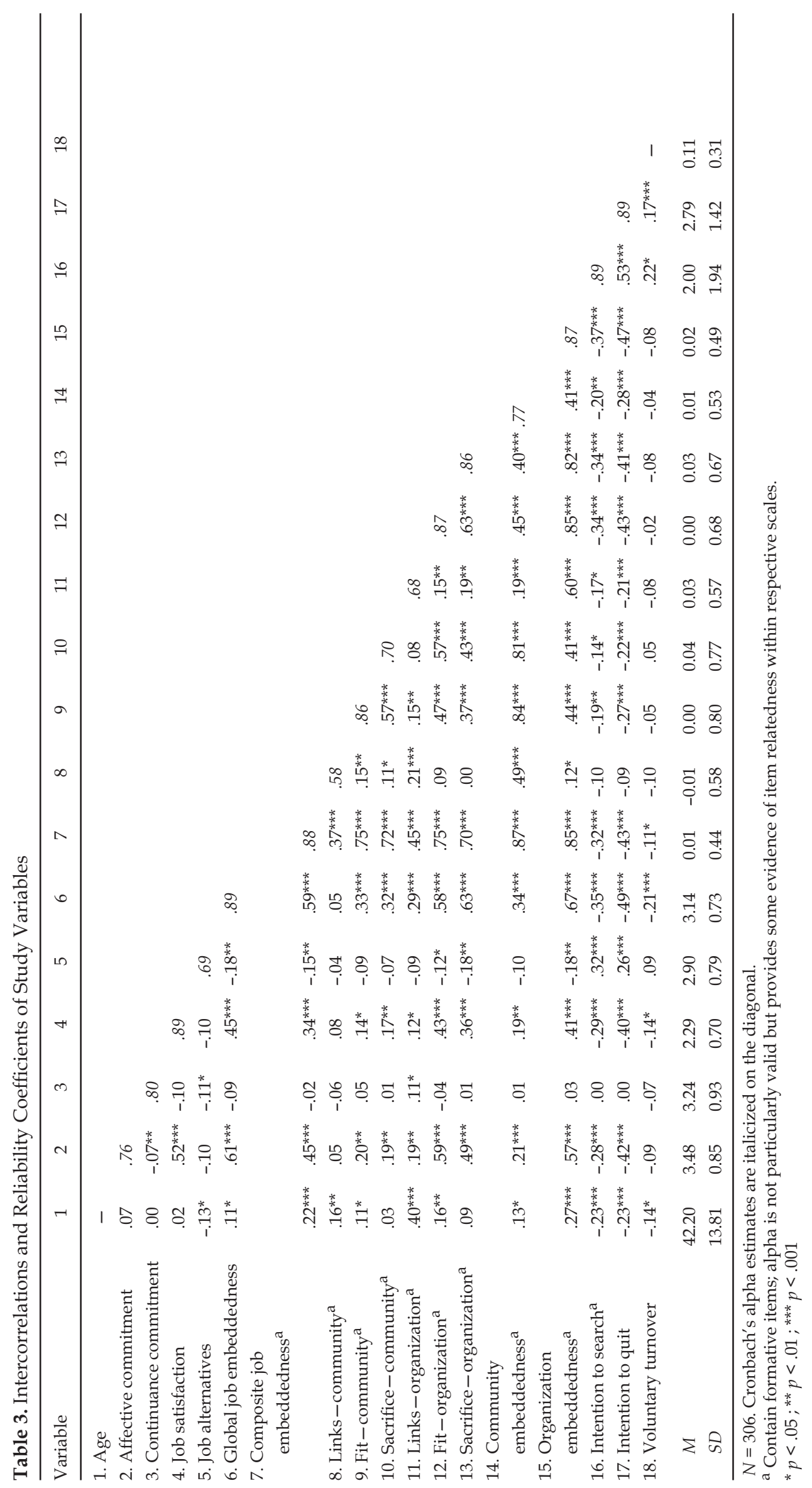


ceptions of being embedded are likely to be based on some, if not all, of the facets comprising the composite measure of job embeddedness, the pattern of moderate to strong correlations between global job embeddedness and first-level organization and community facets provides evidence of convergent validity. The pattern of correlations between global embeddedness and community facets supports the notion that global embeddedness is based on reflections of community embeddedness and that although the global measure did not specifically assess community-related issues, global reflections of embeddedness were, to some extent, based on community issues. Although global job embeddedness shared meaningful variance with community facets, the correlations were smaller than between these facets and the composite measure, suggesting that community facets may be overweighted in the composite scale among some samples or that the whole is not equal to the sum of the parts. Consistent with prior conceptual arguments, global job embeddedness demonstrated stronger correlations with specific community facets than did other forms of attachment (i.e., job satisfaction, affective and continuance commitment, perceived alternatives, and intentions to quit), suggesting that embeddedness is a broader construct that incorporates community- and job-related issues. Beyond convergent relations with facet scales, the positive relations between global embeddedness and second-level facets of organization and community embeddedness ( $r \mathrm{~s}=.67, .34$, respectively) and the composite measure of job embeddedness $(r=.59)$ offer additional evidence of convergent validity. These findings suggest that people weigh organizational factors more heavily when assessing how attached they are to their organization. The sizable correlation with community-related embeddedness provides additional support for the importance of nonwork factors in shaping employees' perceptions of work attachment and supports notions of crossover effects. The strong correlation between global and composite embeddedness provides evidence that these measures converge on the same construct, but the correlation was not so large as to suggest complete overlap.

Although job embeddedness is not necessarily an affective construct, the positive correlations with job satisfaction (.45) and affective commitment (.61) and a negative relation with perceived alternatives (-.18) are consistent with meta-analytic findings regarding the affective underpinnings of job perceptions and attitudes (Thoresen, Kaplan, Barsky, Warren, \& de Chermont, 2003), offering further evidence of convergent validity. The positive correlations with satisfaction and affective commitment suggest that affect-related motives were among the most common forms of attachment, consistent with findings from Maertz and Campion (2004), but the correlations were not so large as to suggest that these measures were assessing the same construct. Continuance commitment was not significantly related to either the composite or the global measure of embeddedness. Although meta-analytic findings have failed to support consistent correlations between continuance commitment and other variables, such as turnover intentions (correlations ranged from .00 to -.42; Allen \& Meyer, 1996), the absence of significant relations between continuance commitment and job embeddedness in the present study contrasts with previous findings (Mitchell et al., 2001). Notwithstanding this somewhat peculiar finding, the overall pattern of correlations with other variables provides support for convergent validity and suggests that affective motives for attachment (e.g., job satisfaction, affective commitment) were strongly related to how embedded people felt. Furthermore, the pattern and magnitude of correlations between global job embeddedness and Mitchell et al.'s (2001) facet and composite measures provide strong evidence of convergence between the original and global measures. In line with arguments forwarded by Ironson et al. (1989), the fact that third variables were more strongly related to global than to composite job embeddedness again suggests that the global whole is greater than the sum of the composite parts. Although these findings together provide substantial support for the global job embeddedness measure, hypothesis tests below place global job embeddedness within its nomological network of related variables and provide more rigorous tests of construct validity.

To provide evidence of discriminant validity, we subjected facet and global measures of job embeddedness, along with measures of job satisfaction, affective and continuance commitment, perceived job alternatives, and intentions to quit, to exploratory factor analysis. Because of the formative nature of the original job embeddedness measure and use of causal indicators, a confirmatory factor analysis was inappropriate (MacKenzie et al., 2005). Furthermore, given the rather low factor loadings of some items (less than .10) reported in previous research (Mitchell et al., 2001), it is unlikely that a well fitting confirmatory model would be attainable. A principalfactors analysis with oblique rotation resulted in a 12-factor solution (eigenvalues $>1$ ) that explained $54.3 \%$ of the total variance. Items from each of the job embeddedness facets loaded on 6 factors that were predominately represented by items from the respective scales. In addition, items from the job satisfaction, affective and continuance commitment, perceived alternatives, and intention to quit scales generally loaded on 5 distinct factors, as expected. It is particularly noteworthy that the global job embeddedness items produced a unique factor that was distinct from all other measures. These results provide initial evidence of discriminant validity.

To provide further evidence of the distinction of job embeddedness from organizational commitment and intentions to quit, we had 97 people (53\% male; $M$ age $=42.7, S D=11.00$ ) from a variety of occupations who had registered with the Internet surveying service Study Response (http:/ / istprojects.syr. edu/ studyresponse/studyresponse/index.htm) complete a survey including the seven-item measure of job embeddedness, the six-item measures of affective and normative commitment, the eight-item measure of continuance commitment (Meyer \& Allen, 1997) and the five-item intention to quit scale. As seen in Table 4, results from a principal-factors analysis found that the job embeddedness items loaded on a distinct factor. Furthermore, the three forms of commitment largely loaded on separate factors, and intent to quit items also loaded on a unique factor that was distinct from job embeddedness and commitment. That the job embeddedness factor accounted for the greatest amount of variance generally confirms the notion that job embeddedness is a broader construct than specific motives of attachment, such as calculative, affective, and normative reasons. Job embeddedness related positively to affective commitment (.74), continuance commitment (.25), and normative commitment (.74) and negatively to intentions to quit $(-.51$, all $p \mathrm{~s}<.05)$. Although these correlations are strong enough to suggest convergence, results from the factor analysis and the fact that job embeddedness predicted unique variance in quit intentions ( $\beta$ $=-.27, p<.05$ ) over all three forms of commitment suggest that job embeddedness is a meaningful and distinct construct. 
Table 4. Results of Exploratory Factor Analysis of Job Embeddedness, Organizational Commitment, and Intentions to Quit

\begin{tabular}{|c|c|c|c|c|c|c|}
\hline \multirow[b]{2}{*}{ Item } & \multicolumn{5}{|c|}{ Factor } & \multirow[b]{2}{*}{$\mathrm{AC}$} \\
\hline & GJE & $\mathrm{CC}$ & ITQ & $\mathrm{NC}$ & RS & \\
\hline AC1 & .30 & & -.48 & & & \\
\hline AC2 & .38 & & & -.33 & & \\
\hline AC3 & & & & & & .47 \\
\hline AC4 & & & & & .32 & .56 \\
\hline AC5 & & & & & & .60 \\
\hline AC6 & & & & & & .75 \\
\hline CC1 & & .71 & & & & \\
\hline CC2 & & .53 & & -.34 & & \\
\hline CC3 & & .74 & & & & \\
\hline CC4 & & .80 & & & & \\
\hline CC5 & & .68 & & & & \\
\hline CC6 & & .85 & & & & \\
\hline CC7 & & & & & .54 & \\
\hline CC8 & & & & & .66 & \\
\hline NC1 & & & -.40 & -.38 & & \\
\hline NC2 & & & -.47 & & & \\
\hline NC3 & & & & -.71 & & \\
\hline NC4 & & & & -.70 & & \\
\hline NC5 & & & & -.70 & & \\
\hline NC6 & & & & -.58 & & \\
\hline GJE1 & .37 & & & & & \\
\hline GJE2 & .60 & & & & & \\
\hline GJE3 & .62 & & & & & .42 \\
\hline GJE4 & .76 & & & & & \\
\hline GJE5 & .68 & & & & & \\
\hline GJE6 & .71 & & & & & \\
\hline GJE7 & .62 & & & & & \\
\hline ITQ1 & & & .90 & & & \\
\hline ITQ2 & & & .72 & & & \\
\hline ITQ3 & & & .81 & & & \\
\hline ITQ4 & & & .91 & & & \\
\hline ITQ5 & & & .73 & & & \\
\hline Eigen & 12.1 & 4.0 & 2.5 & 1.3 & 0.8 & 0.7 \\
\hline$\Delta \sigma$ & 37.7 & 12.4 & 7.7 & 4.0 & 2.6 & 2.2 \\
\hline
\end{tabular}

Values less than .30 are not displayed. GJE = global job embeddedness; $\mathrm{CC}=$ continuance commitment; ITQ $=$ intent to quit; $\mathrm{NC}=$ normative commitment; $\mathrm{RS}=$ reverse-scored item factor; $\mathrm{AC}=$ affective commitment; Eigen = eigenvalue.

\section{Path Model and Test of Hypotheses}

Because of the formative nature of the composite job embeddedness scale, we tested the hypothesized model using path analysis via LISREL 8.5 (Jöreskog \& Sörbom, 2001). Using the guidelines offered by Anderson and Gerbing (1988), we compared the hypothesized model and several alternative models prior to testing specific hypotheses. Analyses were conducted in the following four phases. In the first phase, a traditional model of turnover was examined as a baseline. In the second phase, global and composite measures of job embeddedness were included in the model, as outlined by study hypotheses and to assess convergent validity. In the third phase, control variables were entered into the model to ensure that effects of job embeddedness were robust and to demonstrate discriminant and predictive validity over existing attachment constructs. In the fourth phase, specific study hypotheses were examined in the ultimately best fitting model, which was generated guided by theory, study hypotheses, and model comparisons.

Phase 1. To ensure that a well fitting model was ultimately possible, we specified a traditional model of turnover on the basis of Bannister and Griffeth's (1986) and Sager, Griffeth, and Hom's (1998) revised version of the Mobley et al. (1978) model. This traditional model (see Figure 1) demonstrated good fit to the data, $\chi^{2}(2, N=306)=5.96, p>.05$ (root-meansquare error of approximation [RMSEA] $=.08$, SRMR $=.03$, CFI $=.98$, adjusted goodness-of-fit index $[\mathrm{AGFI}]=.93$ ), and explained $21 \%$ of the variance in intention to search, $37 \%$ of the variance in intention to quit, and $15 \%$ of the variance in voluntary turnover.

Phase 2. In line with the study hypotheses, composite and global measures of job embeddedness were entered into the model, and direct paths were specified between these measures and turnover-related variables. In line with the buffering hypothesis, a path was also specified between the mean-centered interaction term of job satisfaction and global embeddedness and subsequent intention to search. This hypothesized model demonstrated a very good fit to the data, $x^{2}(4, N=$ $306)=6.80, p>.05($ RMSEA $=.05$, SRMR $=.01, \mathrm{CFI}=.99, \mathrm{AGFI}$ $=.94$ ), and explained an additional $5 \%$ of the variance in intent to search, $6 \%$ in intent to quit, and $5 \%$ in voluntary turnover, over the variables included in the traditional model. These findings provide initial support for the predictive validity and practical utility of the job embeddedness measures.

Although the omnibus addition of these paths significantly enhanced prediction of the model, some direct paths might have been unnecessary in conjunction with possible indirect effects. Therefore, in accordance with common theory-trimming practices (Anderson \& Gerbing, 1988; Mayer \& Gavin, 2005), we independently tested each of the four direct links between global and composite job embeddedness, on the one hand, and subsequent intentions to quit and turnover, on the other, by removing each link in isolation and comparing each reduced model with the model containing all four paths. These results are summarized in Table 5 and suggest that the direct link between composite embeddedness and turnover did not enhance the model. This link was therefore eliminated. All other paths were retained in a revised hypothesized model that demonstrated improved model fit, $\chi^{2}(5, N=306)=10.02, p>.05(\mathrm{RM}-$ $\mathrm{SEA}=.06, \mathrm{SRMR}=.02, \mathrm{CFI}=.99$, $\mathrm{AGFI}=.93)$.

Phase 3. To provide a more rigorous test of the predictive validity of job embeddedness and in an effort to demonstrate further evidence of discriminant validity from existing job attitude and turnover-related variables, we added control variables to the model as follows. First, six direct paths between affective and continuance commitment were specified to intention to search, intention to quit, and voluntary turnover. Next, two paths were specified between both job satisfaction and perceived alternatives, on the one hand, and voluntary turnover, on the other. This control model demonstrated a good fit to the data, $\chi^{2}(3, N=306)=8.50, p>.05($ RMSEA $=$ $.08, \mathrm{SRMR}=.02, \mathrm{CFI}=.99, \mathrm{AGFI}=.89)$, but did not enhance prediction over the revised hypothesized model, $\chi^{2}(2, N=$ 306) $=1.52, p>.05$.

To systematically test and remove nonsignificant control variables in favor of a more parsimonious and theoretically 


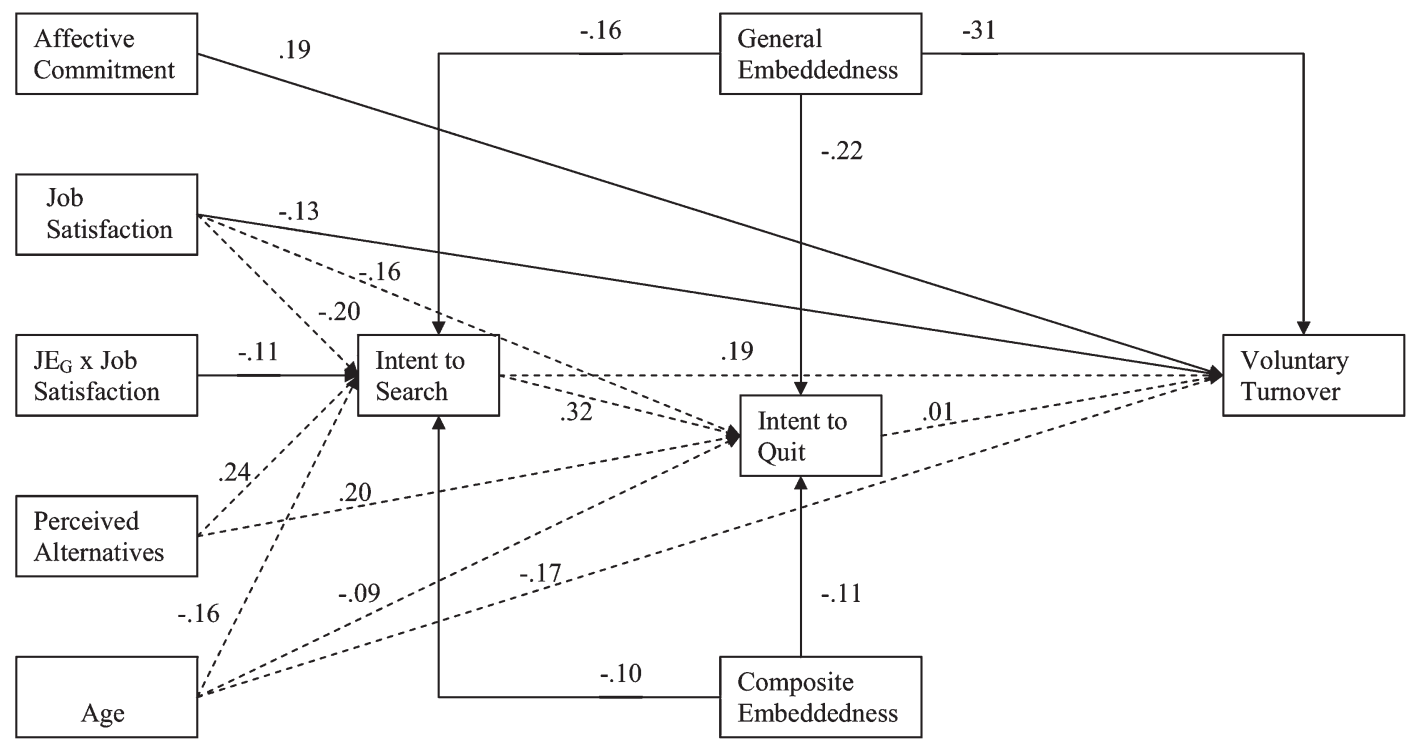

Figure 1. Traditional and final models of voluntary turnover. Values represent standardized path weights. All values are printed above respective paths, with the exception of the path from intent to search and intent to quit. Dashed lines represent paths in Mobley et al.'s (1978) original model of voluntary turnover, and solid lines represent the final model of voluntary turnover. For all values greater than $.08, p<.05$; for values greater than $.16, p<.01$. JEG = global job embeddedness.

derived model, we compared this model with each of eight separate models that removed a single direct path in isolation. As seen in Table 5, only the two paths from control variables to turnover significantly enhanced model fit. None of the pre- viously significant paths between job embeddedness and turnover-related variables became nonsignificant in the presence of control variables. These findings suggest that job embeddedness significantly predicted voluntary turnover over job sat-

Table 5. Results of Structural Nested Model Comparisons

\begin{tabular}{|c|c|c|c|c|c|c|c|}
\hline Model & $x^{2}$ & $d f$ & RMSEA & SRMR & CFI & AGFI & $\Delta \chi^{2}(d f)$ \\
\hline $\mathrm{M}_{\mathrm{H}}$ & 6.80 & 4 & .048 & .013 & .99 & .94 & \\
\hline $\mathrm{M}_{\mathrm{H}}-\mathrm{JE}_{\text {Comp }} \rightarrow$ TO direct path & 10.02 & 5 & .058 & .024 & .99 & .93 & $3.22(1)$ \\
\hline $\mathrm{M}_{\mathrm{H}}-\mathrm{JE}_{\mathrm{Gen}} \rightarrow$ ITQ direct path & 20.45 & 5 & .102 & .029 & .97 & .87 & $13.65(1)^{\mathrm{a}}$ \\
\hline $\mathrm{M}_{\mathrm{H}}-\mathrm{JE}_{\mathrm{Gen}} \rightarrow \mathrm{TO}$ direct path & 25.52 & 5 & .117 & .039 & .96 & .84 & $18.72(1)^{\mathrm{a}}$ \\
\hline $\mathrm{M}_{\mathrm{C}}-\mathrm{JS} \rightarrow \mathrm{TO}$ direct path & 13.28 & 4 & .088 & .023 & .99 & .87 & $4.78(1)^{\mathrm{a}}$ \\
\hline $\mathrm{M}_{\mathrm{C}}-\mathrm{PA} \rightarrow$ TO direct path & 8.53 & 4 & .062 & .016 & .99 & .92 & $0.03(1)$ \\
\hline $\mathrm{M}_{\mathrm{C}}-\mathrm{AC} \rightarrow$ TO direct path & 14.58 & 4 & .094 & .020 & .99 & .86 & $6.08(1)^{\mathrm{a}}$ \\
\hline $\mathrm{M}_{\mathrm{C}}-\mathrm{CC} \rightarrow \mathrm{TO}$ direct path & 11.57 & 4 & .080 & .019 & .99 & .89 & $3.07(1)$ \\
\hline $\mathrm{M}_{\mathrm{C}}-\mathrm{AC} \rightarrow \mathrm{ITQ}$ direct path & 10.28 & 4 & .073 & .017 & .99 & .90 & $1.78(1)$ \\
\hline $\mathrm{M}_{\mathrm{C}}-\mathrm{CC} \rightarrow$ ITQ direct path & 8.53 & 4 & .062 & .016 & .99 & .92 & $0.03(1)$ \\
\hline
\end{tabular}

The traditional model $\left(\mathrm{M}_{\mathrm{TR}}\right)$ is depicted by dashed lines in Figure 1. The hypothesized model $\left(\mathrm{M}_{\mathrm{H}}\right)$ consists of $\mathrm{M}_{\mathrm{TR}}$ plus three direct paths from composite job embeddedness (JE $\mathrm{C}_{\mathrm{Comp}}$ ) to intention to search (ITS), intention to quit (ITQ), and turnover (TO); three direct paths from general job embeddedness $\left(\mathrm{JE}_{\mathrm{Gen}}\right)$ to ITS, ITQ, and TO; and a direct path from Job Satisfaction (JS) $\times \mathrm{JE}_{\mathrm{Gen}}$ to ITS. The revised hypothesized model (M $\left.\mathrm{M}_{\mathrm{HR}}\right)$ is composed of $\mathrm{M}_{\mathrm{H}}$ minus the direct path between composite job embeddedness and turnover. The control model $\left(\mathrm{M}_{\mathrm{C}}\right)$ is composed of $\mathrm{M}_{\mathrm{HR}}$ plus three direct paths from affective commitment (AC) to ITS, ITQ, and TO; three direct paths from continuance commitment (CC) to ITS, ITQ, and TO; and two direct paths from perceived alternatives (PA) and JS to TO. The final model $\left(\mathrm{M}_{\mathrm{F}}\right)$ is composed of $\mathrm{M}_{\mathrm{H}}$ plus two direct paths from JS and from AC to TO. RMSEA = root-mean-square error of approximation; SRMR = standardized root-mean-square residual; $\mathrm{CFI}=\mathrm{comparative} \mathrm{fit}$ index; $\mathrm{AGFI}=$ adjusted goodness-of-fit index.

a The trimmed model (removing a single direct path) significantly enhanced model fit compared with the respective omnibus model. 
isfaction, perceived alternatives, and organizational commitment, thereby providing additional evidence of discriminant and predictive validity. To examine hypotheses beyond these control variables, we specified a final model (see Figure 1) that incorporated the revised hypothesized model plus the two direct paths from satisfaction and affective commitment to voluntary turnover. This final model provided an excellent fit to the data, $\chi^{2}(6, N=306)=10.31, p>.05($ RMSEA $=.05$, SRMR $=$ $.02, \mathrm{CFI}=.99, \mathrm{AGFI}=.94)$.

\section{Test of Hypotheses}

Hypotheses were tested in the final model, which included the hypothesized relations and significant control variables. Hypothesis 1A suggested that job embeddedness would predict intentions to search and to quit over job satisfaction and perceived alternatives. The global measure of embeddedness predicted intent to search $(\beta=-.16, p<.01)$ and intent to quit $(\beta=-.22, p<.01)$, whereas the composite measure predicted intention to quit $(\beta=-.11, p<.05)$. The composite measure of job embeddedness did not predict intent to search $(\beta=-.10, p$ $>.05$ ) in the presence of the global measure and control variables. Hypothesis $1 \mathrm{~B}$ suggested that job embeddedness would predict turnover after job satisfaction, perceived alternatives, and intentions to search and to quit were controlled. This hypothesis was partially supported, as global job embeddedness had a significant and direct relation $(\beta=-.31 p<.01)$ with turnover after these variables were controlled. However, the composite measure did not enhance model fit over these variables and was omitted from the model in earlier stages of testing. It is important to note that this model also controlled for the statistical overlap between global and composite measures of embeddedness and may provide an overly conservative test of this hypothesis. Together, the similar pattern and direction of relations between global and composite measures and subsequent turnover-related variables provides evidence of convergent validity.

Hypothesis 2 suggested that global job embeddedness would predict variance in intent to search, intent to quit, and turnover over the composite measure of job embeddedness. Results confirmed this notion, as global job embeddedness predicted unique variance in intent to search $(\beta=-.16)$, intent to quit $(\beta=-.22)$, and voluntary turnover $(\beta=-.31$, all $p \mathrm{~s}<$ .01 ) after composite job embeddedness and other antecedents and control variables were taken into account.

Hypothesis 3 suggested that global job embeddedness would interact with job satisfaction to predict intention to search. Although the joint term predicted intent to search ( $\beta$ $=-.11, p<.05)$, the nature of this interaction was not as originally anticipated. Figure 2 displays the relationship between job satisfaction and intentions to search for participants who were one standard deviation above or below the mean on general job embeddedness. Analysis of the simple slopes in each group indicated that job satisfaction was significantly and negatively related to intent to search for employees with high job embeddedness $(\beta=-.39, p<.01)$, but there was a nonsignificant relationship between these variables for employees with low job embeddedness $(\beta=-.13)$. Whereas people who reported low levels of job embeddedness engaged in more preparatory search activity than people with high embeddedness scores, as would generally be expected, the relation between satisfaction and search intention was negative rather than neutral among highly embedded employees. This finding suggests

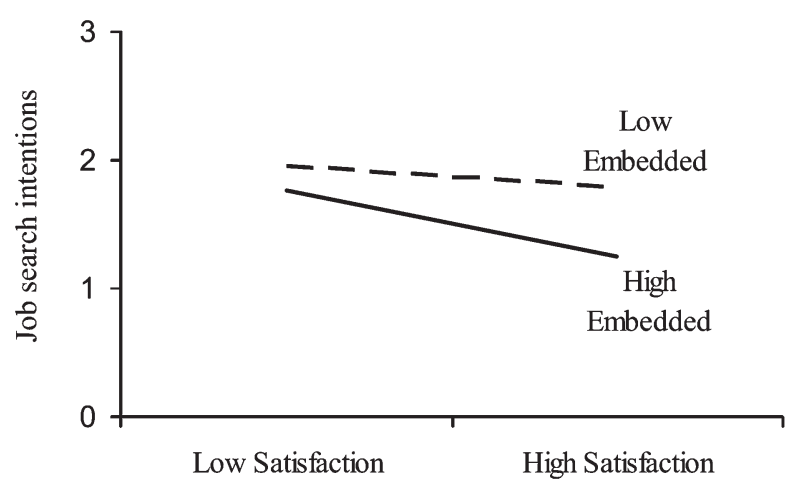

Figure 2. The interaction of general job embeddedness and job satisfaction on job search intentions.

that job embeddedness does not prevent dissatisfied employees from intending to search for alternative employment. Rather, a lack of embeddedness was associated with greater search intentions regardless of satisfaction levels.

\section{Discussion}

In this study, we have developed a global measure of job embeddedness and integrated this construct into a traditional model of turnover. We found that the global measure predicted unique variance in intentions to search, intentions to quit, and voluntary turnover, even after we controlled for empirical overlap in the composite measure of embeddedness and other core variables commonly used to explain turnover. Aside from direct relations between embeddedness and turnover that support prior research (Lee et al., 2004; Mitchell et al., 2001), the significant interaction with satisfaction contrasts earlier conclusions by Mitchell et al. (2001) that "because job embeddedness correlates significantly with search behaviors..., it can be inferred that highly embedded people search less" ( $p$. 1117). Findings from the present study suggest that this statement be qualified such that highly embedded and satisfied people search less. Findings also suggest that job embeddedness may prohibit decision processes that often precede volitional separation and can be meaningfully integrated into traditional models of turnover.

Although these findings suggest that both composite and global measures of embeddedness predict meaningful variance in turnover, the choice of measures in subsequent research is best made in the context of the particular study. For instance, the more contextual nature of the composite measure may help reduce concerns of percept-percept inflation in selfreport, cross-sectional studies. Conversely, the global measure is of greater utility when one is testing models of turnover using latent variables or when survey length is a concern. Using both scales together avoids issues of singularity between facets and global embeddedness and allows an examination of the relative weight of each facet in overall impressions of embeddedness.

\section{Practical Implications}

Whereas global embeddedness proved useful in predicting intentions to search and quit as well as voluntary turnover, organizations may benefit from helping employees feel 
connected at work and at home. Related to community embeddedness, work parties and informal get-togethers that promote community attractions and leisure activities may help people bond to the community, thereby having an impact beyond the obvious social benefits. Organizations that offer flexible scheduling and family friendly programs may further enhance employee embeddedness by strengthening employees' social bonds to others within the community. Beyond social exchange and organizational support, this may help explain why companies with such benefits experience lower turnover. One potential downside of job embeddedness that warrants consideration is that people who feel stuck in an unfavorable job may lose motivation, experience frustration, and even engage in counterproductive workplace behaviors.

\section{Limitations and Future Research}

There are several limitations to the present study that should be taken into consideration. One limitation is the reliance on a questionnaire study and convenience samples. Although artificially inflated relationships due to percept-percept and common method biases can often lead to invalid conclusions, common method bias inherent in self-report surveys actually provided a more conservative test of some study hypotheses, as job embeddedness was found to uniquely predict voluntary turnover over job satisfaction, organizational commitment, behavioral intentions, and empirical overlap in these variables due to common method variance. Furthermore, the significant interaction between job satisfaction and embeddedness in predicting intention to search helps mitigate concerns of percept-percept inflation. Although convenience samples were used to provide evidence of construct validity, the emergence of similar results across studies helps reduce concerns of limited generalizability. Nevertheless, we recognize that construct validity is never accomplished in a single study and that future research is needed to replicate results across other samples, organizations, work contexts, and study designs.

It is essential to recognize that although the longitudinal nature of the study offers support for the direction of relations among the study's variables, assumptions of causality cannot be made because of the potential existence of common third variables, many of which we attempted to control. Another limitation is that results from this study are based on relatively subtle adjustment of Mobley et al.'s (1978) traditional model of turnover and the specific measures used in previous research. Adaptations to the model and measures were based on subsequent research conducted in more recent years (e.g., Bannister \& Griffeth, 1986; Steel \& Griffeth, 1989). Nevertheless, it is difficult to distinguish the extent to which these differences might have affected the study results. Finally, although removal of nonsignificant paths is a common theory-trimming practice, this may lead to sample-specific findings. Although we took caution to modify the model according to theory and previous empirical findings, additional research is necessary before we can place full confidence in the final model derived in this study.

Because global perceptions of job embeddedness are largely subjective and may be influenced by people's predispositions and cognitive frames, future research may examine individual differences that relate to impressions of being embedded. For instance, trait negative affectivity is marked by a tendency to dwell on negative aspects of the self and world. People who are high in this trait may underestimate the number of alternative jobs or their value to prospective employers, thereby influencing the extent to which they feel stuck in their job. Another personality trait that may be relevant in the study of embeddedness and turnover is a need for achievement. Along these lines, engineers, accountants, and middle managers with high need for achievement have been found to have higher mobility rates (Hines, 1973). Perhaps high achievers are less likely to perceive themselves as embedded, or they may have a heightened interest in searching for ways to advance outside of the organization.

\section{Conclusion}

This study offers initial evidence of the validity of a global measure of job embeddedness. This measure overcomes several limitations of the original composite scale and predicted additional variance in voluntary turnover beyond the composite measure of embeddedness and over core constructs included in traditional models of turnover. Together, these findings provide initial evidence of construct validity and highlight the importance of examining job embeddedness as a unique contributor to decision-making processes. Moreover, this measure is useful for researchers interested in studying the role of general attachment in broader theories of job mobility.

\section{References}

Allen, N. J., \& Meyer, J. P. (1990). The measurement and antecedents of affective, continuance, and normative commitment to the organization. Journal of Occupational Psychology, 63, 1-18.

Allen, N. J., \& Meyer, J. P. (1996). Affective, continuance, and normative commitment to the organization: An examination of construct validity. Journal of Vocational Behavior, 49, 252-276.

Anderson, J. C., \& Gerbing, D. W. (1988). Structural equation modeling in practice: A review and recommended two-step approach. Psychological Bulletin, 103, 411-423.

Bannister, B. D., \& Griffeth, R. W. (1986). Applying a causal analytic framework to the Mobley, Horner, and Hollingsworth (1978) turnover model: A useful reexamination. Journal of Management, 12, 433-443.

Blau, G. (1994). Testing a two-dimensional measure of job search behavior. Organizational Behavior and Human Decision Processes, 59, 288-312.

Breaugh, J. A., \& Colihan, J. P. (1994). Measuring facets of job ambiguity: Construct validity evidence. Journal of Applied Psychology, 79, 191-202.

Crossley, C. D., Grauer, E., Lin, L. F., \& Stanton, J. M. (2002, April). Assessing the content validity of intention to quit scales. Paper presented at the annual meeting of the Society for Industrial and Organizational Psychology, Toronto, Ontario, Canada.

Crossley, C. D., \& Stanton, J. M. (2005). Negative affect and job search: Further examination of the reverse causation hypothesis. Journal of Vocational Behavior, 66, 549-560.

Endler, N. S., Macrodimitris, S. D., \& Kocovski, N. L. (2000). Controllability in cognitive and interpersonal tasks: Is control good for you?Personality and Individual Differences, 29, 951-962.

Fishbein, M., \& Ajzen, I. (1975). Belief, attitude, intention, and behavior: An introduction to theory and research. Reading, MA: Addison-Wesley. 
Harvey, R. J., Billings, R. S., \& Nilan, K. J. (1985). Confirmatory factor analysis of the Job Diagnostic Survey: Good news and bad news. Journal of Applied Psychology, 70, 461-468.

Hines, G. H. (1973). Achievement motivation, occupations, and labor turnover in New Zealand. Journal of Applied Psychology, 58, 313-317.

Hinkin, T. R. (1995). A review of scale development practices in the study of organizations. Journal of Management, 21, 967-988.

Holtom, B. C., Mitchell, T. R., Lee, T. W., \& Interrieden, E. J. (2005). Shocks as causes of turnover: What they are and how organizations can manage them. Human Resource Management, 44, 337-352.

Ironson, G. H., Smith, P. C., Brannick, M. T., Gibson, W. M., \& Paul, K. B. (1989). Construction of a job in general scale: A comparison of global, composite, and specific measures. Journal of Applied Psychology, 74, 193-200.

Jöreskog, K. G., \& Sörbom, D. (2001). LISREL 8.5: User's reference guide [Computer software and manual]. Chicago, IL: Scientific Software International.

Katzell, R. A., Korman, A. K., \& Levine, E. L. (1971). Overview study of the dynamics of worker job mobility. Washington, DC: Social and Rehabilitation Services, U.S. Department of Health, Education and Welfare.

Kristof, A. (1996). Person-organization fit: An integrative review of its conceptualization, measurement, and implications. Personnel Psychology, 49, 1-50.

Lee, T. W., \& Mitchell, T. R. (1994). An alternative approach: The unfolding model of voluntary employee turnover. Academy of Management Review, 19, 51-89.

Lee, T. W., Mitchell, T. R., Sablynski, C. J., Burton, J. P., \& Holtom, B. C. (2004). The effects of job embeddedness on organizational citizenship, job performance, volitional absences, and voluntary turnover. Academy of Management Journal, 47, 711-722.

Lewin, K. (1951). Field theory in social science. New York: Harper.

MacKenzie, S. B., Podsakoff, P. M., \& Jarvis, C. B. (2005). The problem of measurement model misspecification in behavioral and organizational research and some recommended solutions. Journal of Applied Psychology, 90, 710-730.

Maertz, C. P., Jr., \& Campion, M. A. (2004). Profiles in quitting: Integrating process and content turnover theory. Academy of Management Journal, 47, 566-582.

March, J. G., \& Simon, H. A. (1958). Organizations. New York: Wiley.

Mayer, R. C., \& Gavin, M. B. (2005). Trust in management and performance: Who minds the shop while the employees watch the boss?Academy of Management Journal, 48, 874-888.

Meyer, J. P., \& Allen, N. J. (1997). Commitment in the workplace: Theory, research and application. Thousand Oaks, CA: Sage.

Mitchell, T. R., Holtom, B. C., Lee, T. W., Sablynski, C. J., \& Erez, M. (2001). Why people stay: Using job embeddedness to predict voluntary turnover. Academy of Management Journal, 44, 1102-1121.

Mitchell, T. R., \& Lee, T. W. (2001). The unfolding model of voluntary turnover and job embeddedness: Foundations for a comprehensive theory of attachment. Research in Organizational Behavior, 23, 189-246.

Mobley, W. H. (1977). Intermediate linkages in the relationship between job satisfaction and employee turnover. Journal of Applied Psychology, 62, 237-240.
Mobley, W. H., Horner, S. O., \& Hollingsworth, A. T. (1978). An evaluation of precursors of hospital employee turnover. Journal of Applied Psychology, 63, 408-414.

Mossholder, K. W., Settoon, R. P., \& Henagan, S. C. (2005). A relational perspective on turnover: Examining structural, attitudinal, and behavioral predictors. Academy of Management Journal, 48, 607-618.

Mowday, R. T., Steers, R. M., \& Porter, L. W. (1979). The measurement of organizational commitment. Journal of Vocational Behavior, 14, 224-247.

Muchinsky, P. M., \& Morrow, P. C. (1980). A multidisciplinary model of voluntary turnover. Journal of Vocational Behavior, 17, 263-290.

Podsakoff, P. M., MacKenzie, S. B., Lee, J., \& Podsakoff, N. P. (2003). Common method biases in behavioral research: A critical review of the literature and recommended remedies. Journal of Applied Psychology, 88, 879-903.

Price, J. L. (1977). The study of turnover. Ames: Iowa State University Press.

Rice, R. W., Gentile, D. A., \& McFarlin, D. B. (1991). Facet importance and job satisfaction. Journal of Applied Psychology, 76, 31-39.

Russell, S. S., Spitzmüller, C., Lin, L. F., Stanton, J. M., Smith, P. C., \& Ironson, G. H. (2004). Shorter can also be better: The Abridged Job in General Scale. Educational and Psychological Measurement, 64, 878-893.

Sager, J. K., Griffeth, R. W., \& Hom, P. W. (1998). A comparison of structural models representing turnover cognitions. Journal of Vocational Behavior, 53, 254-273.

Spector, P. E., (1997). Job satisfaction. Thousands Oaks, CA: Sage.

Steel, R. P. (2002). Turnover theory at the empirical interface: Problems of fit and function. Academy of Management Review, 27, 346-360.

Steel, R. P., \& Griffeth, R. W. (1989). The elusive relationship between perceived employment opportunity and turnover behavior: A methodological or conceptual artifact?Journal of Applied Psychology, 74, 846-854.

Steers, R. M., \& Mowday, R. T. (1981). Employee turnover and postdecision accommodation processes. In B. M.Staw \& L. L.Cummings (Eds.), Research in organizational behavior (Vol. 3, (pp. 325-381). Greenwich, CT: JAI Press.

Tett, R. P., \& Meyer, J. P. (1993). Job satisfaction, organizational commitment, turnover intention, and turnover: Path analysis based on meta-analytic findings. Personnel Psychology, 46, 259-293.

Thoresen, C. J., Kaplan, S. A., Barsky, A. P., Warren, C. R., \& de Chermont, K. (2003). The affective underpinnings of job perceptions and attitudes: A meta-analytic review and integration. Psychological Bulletin, 129, 914-945.

Vandenberg, R. J., \& Nelson, J. B. (1999). Disaggregating the motives underlying turnover intentions: When do intentions predict turnover behavior?Human Relations, 52, 1313-1336.

Yao, X., Lee, T. W., Mitchell, T. R., Burton, J. P., \& Sablynski, C. S. (2004). Job embeddedness: Current research and future directions. In R.Griffeth \& P.Hom (Eds.), Understanding employee retention and turnover (pp. 153-187). Greenwich, CT: Information Age. 